\title{
Microsporidia Infection in a Mexican Kidney Transplant Recipient
}

\author{
Oscar Xavier Hernández-Rodríguez, ${ }^{1}$ \\ Octavio Alvarez-Torres, ${ }^{2}$ and Norma Ofelia Uribe-Uribe ${ }^{3}$ \\ ${ }^{1}$ Department of Pathology, Hospital General Regional No. 6, Instituto Mexicano del Seguro Social, 89210 Madero, TAMPS, Mexico \\ ${ }^{2}$ Department of Nephrology, Hospital de Beneficencia Española, 89120 Tampico, TAMPS, Mexico \\ ${ }^{3}$ Department of Pathology, Instituto Nacional de Ciencias Médicas y Nutrición "Salvador Zubirán”, 14000 Mexico City, DF, Mexico
}

Correspondence should be addressed to Oscar Xavier Hernández-Rodríguez, herox7@gmail.com

Received 6 November 2012; Accepted 29 November 2012

Academic Editors: K. Hirayama, K. Nozu, and L. Zuo

Copyright ( 2012 Oscar Xavier Hernández-Rodríguez et al. This is an open access article distributed under the Creative Commons Attribution License, which permits unrestricted use, distribution, and reproduction in any medium, provided the original work is properly cited.

\begin{abstract}
Microorganisms of the microsporidia group are obligated intracellular protozoa that belong to the phylum Microspora; currently they are considered to be related or belong to the fungi reign. It is considered an opportunistic infection in humans, and 14 species belonging to 8 different genera have been described. Immunocompromized patients such as those infected with human immunodeficiency virus (HIV), also HIV serum-negative asymptomatic patients, with poor hygienic conditions, and recipients of bone marrow or solid organ transplantation are susceptible to develop deinfection. Sixty transplanted patients with renal microsporidia infection have been reported worldwide. The aim of this paper is to inform about the 2 nd case of kidney transplant and microsporidia infection documented in Mexico.
\end{abstract}

\section{Introduction}

Microsporidia is an intracellular obligated protozoon, which belongs to the Microspora phylum. There are about 140 genera and 1,200 species of microsporidia, which affects human being and animals. It is considered as opportunistic infections in humans, and 14 species from 8 genera have been reported infecting humans. Encephalitozoon, Enterocytozoon, Pleistophora, Tachipleistophora, Nosema, Vittaforma, Brachiola, and Microsporidium, the last one includes not classified species [1-3].

The identification of these protozoa as an opportunistic pathogen has been described in HIV-infected patients with AIDS, and chronic diarrhea and fever are the most frequent manifestations in Mexican patients with AIDS (present in approximately $30 \%$ of the cases) [4]. Most of the intestinal infection is caused by Encephalitozoon intestinalis and Enterocytozoon bieneusi [2, 5, 6]. Infection by the protozoa has been informed also in healthy people with low socioeconomic status and poor hygienic conditions, mainly who usually drink non-treated water it has been demonstrated waterborne transmission; for this reason, it is considered a potential community risk. This has also been demonstrated in a study in 2 Mexican communities $[5,7]$.

Other several cases of microsporidia infection have been described in HIV negative, solid organ transplant recipients. In these cases, it is not clear if the infection was transmitted by the donor or if the immunosuppression favored an infection acquired in the community $[8,9]$. There are several diagnostic techniques for microsporidia detection, among them histochemistry and immunohistochemistry; nevertheless, electron microscopy confirms the diagnosis and identifies the species. Complementary studies such as molecular and antigenic probes are very useful $[3,10]$.

The aim of this paper is to inform an infrequent case of microsporidia nephritis in a kidney transplant recipient.

\section{Case Report}

A 52 year-old male with type 2 diabetes mellitus, who developed end stage renal disease, received a deceased 


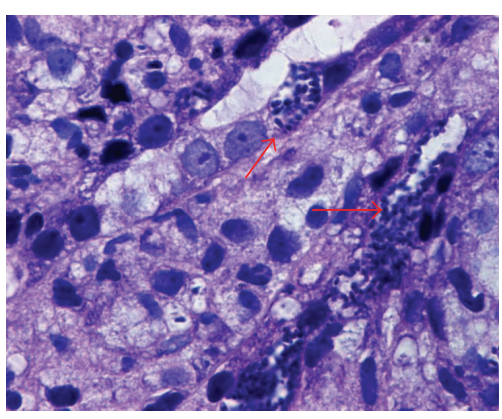

(a)

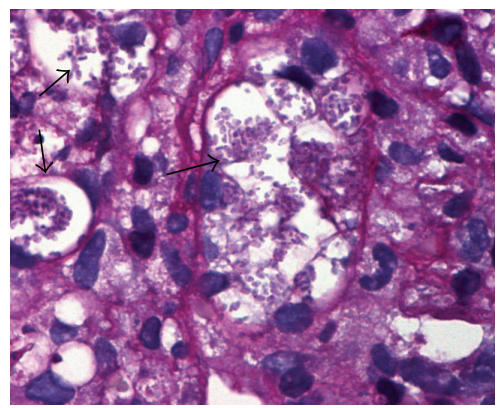

(b)

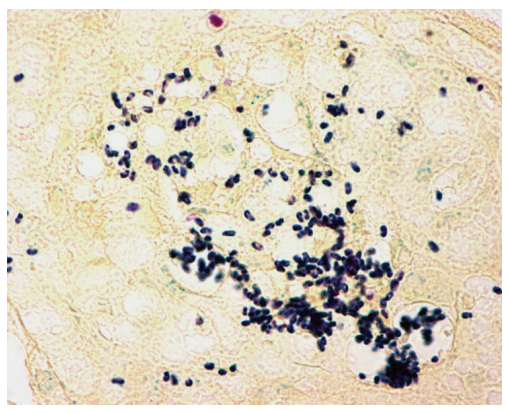

(c)

Figure 1: (a) H\&E stain: tubular epithelial cells show parasitophorous vacuoles, with abundant microsporidia spores (arrow). (b) Spores are not strongly stained with the PAS stain. (c) Warthin Starry stain strongly stains the spore.

donor kidney transplant. The starting immunosuppressant was Tacrolimus, Prednisone, and mycophenolate mofetil. It is important to mention that the donor had history of drug abuse, it is ignored what kind of drug and time of consumption. The donor died knocked down by a car. The recipient who received the other kidney developed fever and died, and the cause of the fever was not determined. In the present case, the patient developed persistent fever $\left(38.5^{\circ} \mathrm{C}\right) 5$ months after transplantation and renal dysfunction with serum creatinine of $1.2 \mathrm{mg} / \mathrm{dL}$ increasing to $4.7 \mathrm{mg} / \mathrm{dL}$ at the moment of the biopsy. The urianalysis demonstrated scanty yeast (nonspecific). Acute rejection and possible tuberculosis were suspected. Antibiotics and antituberculosis drugs were empirically given. White blood cell count: $5.14 \times 10^{3} / \mu \mathrm{L}$. Three months later kidney biopsy was taken. Doses of immunosuppressant were tacrolimus $1 \mathrm{mg}$ every 12 hours and Prednisone $10 \mathrm{mg}$ every 24

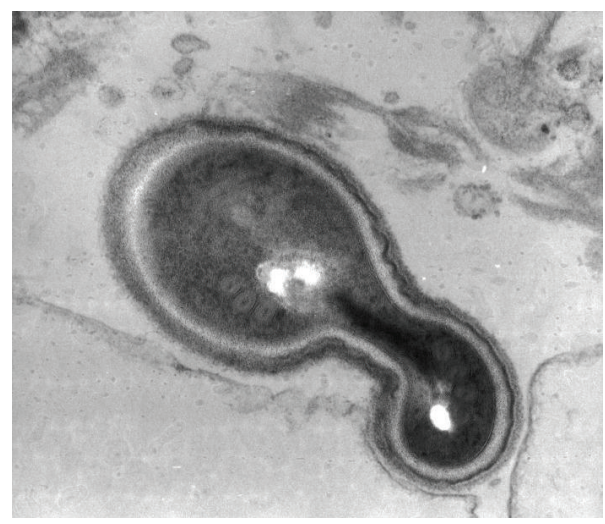

(a)

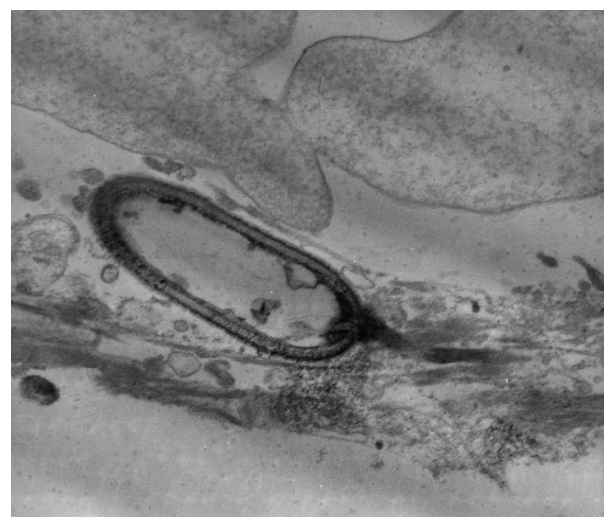

(b)

Figure 2: (a) Transmission electron microscopy demonstrates the presence of the meront of microsporidia, with the characteristic coiled polar tube. (b) Microsporidia meront hat shows the polar tube distended.

hours. White blood cell count was $1.8 \times 10^{3} / \mu \mathrm{L}$. The renal biopsy disclosed a granulomatous nephritis without caseous necrosis occupying $60 \%$ of the interstitial area, granulomas were observed surrounding tubules, many parasitophorous vacuoles were present in tubular epithelial cells, and within these vacuoles plenty microsporidian spores were identified, but they were also found in the luminal space (Figure 1(a)). The microorganisms were best seen with Warthin-Starry (Figure 1(c)) and modified Gram satins; posterior vacuole was identified with PAS stain (Figure 1(b)). Immunomarking with antibody against toxoplasma gondii was negative. Electron microscopy revealed the characteristic ultrastructure of microsporidia spores, exospore, endospore and a coiled polar tubule were identified (Figure 2(a)), and there were also several microsporidia that showed extended polar tube (Figure 2(b)); this finding as well as the development of aninside parasitophorous vacuole is observed in E. intestinalis, E. hellem, and E. cuniculi [3]. There were no histological data of rejection.

The patient was treated with albendazole without improvement. Transplant nephrectomy was done, and immunosuppressive therapy was withdrawn; grossly the kidney was edematous, corticomedullary junction was unclear, 
and a small cortical infarction was identified in the upper pole (possibly related to the previous biopsy). There was an improvement in the patient's condition and fever decrease four days after the nephrectomy. The light microscopy findings were similar to those observed in biopsy.

\section{Discussion}

Sixty cases of microsporidia infection in bone marrow and solid organ transplant recipients have been informed all over the word since 1993 [11-34]. The highest informed prevalence has been reported in France with 40 cases [1118], 26 of them in kidney transplant recipients, followed by Holland [19] and USA [20-25] with 5 cases each; the following countries have reported 2 cases each: Germany $[26,27]$, India [28, 29], Spain [30], and Mexico [31] including the present case, both Mexican cases in kidney transplant recipients. One case has been reported in Canada [32], South Africa [33], and Australia [34]. Even when the majority of the cases of microsporidiosis in solid organ transplantation correspond to kidney transplant receptors, kidney involvement is observed in a minority of cases typically as a part of systemic infection $[18,22,31-33]$, and only 7 out of 39 informed cases (17\%) [22, 30, 33] with kidney involvement manifested with renal dysfunction.

Clinically, most microsporidia infection presents with diarrhea and weight loss. However, microsporidia have been detected virtually in all organs and may provoke symptoms related to their specific localization, and clinical syndromes associated include enteropathy, keratoconjunctivitis, sinusitis, tracheobronchitis, encephalitis, interstitial nephritis, hepatitis, cholecystitis, osteomyelitis, and myositis [35]. The case from South Africa [33] and the present case had fever and renal dysfunction only, suggesting the affection of this organ only. In the present case, the donor had history of drug abuse, and the recipient who received the other kidney developed fever of unknown origin and died; this antecedent suggests the possibility that the donor had microsporidiosis, and the transplanted kidneys carried out the infection to both recipients. This case, as well as other similar cases, encourages us to consider organ transplant recipients as a risk group for microsporidiosis; a systemic search is recommended for these protozoa in cases of transplant recipients with persistent diarrhea and fever of unknown origin, or any of the above cited syndromes [35].

The diagnosis of microsporidiosis is made histologically, either from tissue biopsies or secretions. The development of inside parasitophorous vacuole is observed in E. intestinalis, E. hellem, and E. cuniculi infection [3]. Transmission electron microscopy (TEM) was used to confirm the diagnosis, based on revealing characteristic ultrastructural features such as the coiled polar tube within spores and posterior vesicle characteristic of microsporidia [3]. TEM along with special stains and light microscopy, as well as immunohistochemical and molecular techniques, is capable of providing a firm diagnosis, and taxonomic organization of the microsporidia $[3,10]$.
Encephalitozoon species typically are responsible for disseminated infections [3]; E. intestinalis and E. cuniculi are the most common microsporidia infecting the kidney [1$3,8]$; from the 7 cases with kidney involvement, 4 (57\%) were related with Encephalitozoon cuniculi, and one (14\%) E. Intestinalis [18, 22, 31-33]; in the other cases Encephalitozoon was identified, but the species was not determined [34]. Possibly E. cuniculi has more avidity for renal tissue [18, 22, $31,32]$.

\section{Conclusions}

Not only HIV immunosuppressed patients should be considered at risk for microsporidia infections, but also immunosuppressed patients such as solid organ transplanted patients must be considered in this group also.

A systemic search is commended for these protozoa in cases of transplant recipients with persistent diarrhea or fever of unknown origin.

This is the second case of microsporidiosis, reported in Mexico, both of them in kidney transplant recipient. The present case had no systemic manifestations of the infection, with transplant dysfunction and fever.

\section{References}

[1] R. B. Colvin, "Fungal: ricketsial, and parasitic infections of the kidney: microsporidiosis," in Diagnostic Pathology. Kidney Diseases, A. Chang, A. B. Farris, N. Kambham, L. D. Cornell, and S. H. Meehan, Eds., pp. 5-56, Amyrsis Publishing Inc, Altona, Canada, 2011.

[2] R. Weber, R. T. Bryan, D. A. Schwartz, and R. L. Owen, "Human microsporidial infections," Clinical Microbiology Reviews, vol. 7, no. 4, pp. 426-461, 1994.

[3] E. S. Didier and L. M. Weiss, "Microsporidiosis: current status," Current Opinion in Infectious Diseases, vol. 19, no. 5, pp. 485-492, 2006.

[4] A. Gamboa-Dominguez, C. Bencosme Viñas, and M. Kato Maeda, "Microsporidiasis en pacientes con sida y diarrea crónica, Experiencia en el Instituto Nacional De La Nutrición "Salvador Zubirán"', Revista de Gastroenterologia de Mexico, vol. 64, no. 2, pp. 70-74, 1999.

[5] L. Cotte, M. Rabodonirina, F. Chapuis et al., "Waterborne outbreak of intestinal microsporidiosis in persons with and without human immunodeficiency virus infection," Journal of Infectious Diseases, vol. 180, no. 6, pp. 2003-2008, 1999.

[6] A. Cali, D. P. Kotler, and J. M. Orenstein, "Septata intestinalis, an intestinal microsporidian associated with chronic diarrhea and dissemination in AIDS patients," The Journal of Eukaryotic Microbiology, vol. 40, no. 1, pp. 101-112, 1993.

[7] F. Javier Enriquez, D. Taren, A. Cruz-López, M. Muramoto, J. D. Palting, and P. Cruz, "Prevalence of intestinal encephalitozoonosis in Mexico," Clinical Infectious Diseases, vol. 26, no. 5, pp. 1227-1229, 1998.

[8] R. S. Barsoum, "Parasitic infections in organ transplantation," Experimental and Clinical Transplantation, vol. 2, no. 2, pp. 258-267, 2004.

[9] R. Weber and R. T. Bryan, "Microsporidial infections in immunodeficient and immunocompetent patients," Clinical Infectious Diseases, vol. 19, no. 3, pp. 517-521, 1994. 
[10] L. S. Garcia, "Laboratory identification of the microsporidia. Minireview," Journal of Clinical Microbiology, vol. 40, no. 6, pp. 1892-1901, 2002.

[11] O. Liguory, C. Sarfati, F. Derouin, and J. M. Molina, "Evidence of different Enterocytozoon bieneusi genotypes in patients with and without human immunodeficiency virus infection," Journal of Clinical Microbiology, vol. 39, no. 7, pp. 2672-2674, 2001.

[12] M. Rabodonirina, L. Cotte, S. Radenne, E. Besada, and C. Trepo, "Microsporidiosis and transplantation: a retrospective study of 23 cases," Journal of Eukaryotic Microbiology, vol. 50, p. $583,2003$.

[13] M. Rabodonirina, M. Bertocchi, I. Desportes-Livage et al., "Enterocytozoon bieneusi as a cause of chronic diarrhea in a heart-lung transplant recipient who was seronegative for human immunodeficiency virus," Clinical Infectious Diseases, vol. 23, no. 1, pp. 114-117, 1996.

[14] A. Guerard, M. Rabodonirina, L. Cotte et al., "Intestinal microsporidiosis occurring in two renal transplant recipients treated with mycophenolate mofetil," Transplantation, vol. 68, no. 5, pp. 699-701, 1999.

[15] S. Metge, J. Tran Van Nhieu, D. Dahmane et al., "A case of enterocytozoon bieneusi infection in an HIV-Negative renal transplant recipient," European Journal of Clinical Microbiology and Infectious Diseases, vol. 19, no. 3, pp. 221-223, 2000.

[16] J. M. Molina, M. Tourneur, C. Sarfati et al., "Fumagillin treatment of intestinal microsporidiosis," New England Journal of Medicine, vol. 346, pp. 1963-1969, 2002.

[17] F. Lanternier, D. Boutboul, J. Menotti et al., "Microsporidiosis in solid organ transplant recipients: two Enterocytozoon bieneusi cases and review," Transplant Infectious Disease, vol. 11, pp. 83-88, 2009.

[18] H. Talabani, C. Sarfati, E. Pillebout, T. Van Gool, F. Derouin, and J. Menotti, "Disseminated infection with a new genovar of Encephalitozoon cuniculi in a renal transplant recipient," Journal of Clinical Microbiology, vol. 48, no. 7, pp. 2651-2653, 2010.

[19] R. J. Ten Hove, L. Van Lieshout, M. B. J. Beadsworth et al., "Characterization of genotypes of enterocytozoon bieneusi in immunosuppressed and immunocompetent patient groups," Journal of Eukaryotic Microbiology, vol. 56, no. 4, pp. 388-393, 2009.

[20] P. E. Sax, J. D. Rich, W. S. Pieciak, and Y. M. Trnka, "Intestinal microsporidiosis occurring in a liver transplant recipient," Transplantation, vol. 60, no. 6, pp. 617-618, 1995.

[21] T. Gumbo, R. E. Hobbs, C. Carlyn, G. Hall, and C. M. Isada, "Microsporidia infection in transplant patients," Transplantation, vol. 67, no. 3, pp. 482-484, 1999.

[22] M. N. Mahmood, M. E. Keohane, and E. M. Burd, "Pathologic quiz case: a 45-year-old renal transplant recipient with persistent fever," Archives of Pathology \& Laboratory Medicine, vol. 127, no. 4, pp. e224-e226, 2003.

[23] J. M. Orenstein, P. Russo, E. S. Didier, C. Bowers, N. Bunin, and D. T. Teachey, "Fatal pulmonary microsporidiosis due to Encephalitozoon cuniculi following allogeneic bone marrow transplantation for acute myelogenous leukemia," Ultrastructural Pathology, vol. 29, no. 3-4, pp. 269-276, 2005.

[24] D. T. Teachey, P. Russo, J. M. Orenstein, E. S. Didier, C. Bowers, and N. Bunin, "Pulmonary infection with microsporidia after allogeneic bone marrow transplant," Bone Marrow Transplantation, vol. 33, no. 3, pp. 299-302, 2004.
[25] J. R. Carlson, L. Li, C. L. Helton et al., "Disseminated microsporidiosis in a pancreas/kidney transplant recipient," Archives of Pathology \& Laboratory Medicine, vol. 128, no. 3, pp. e41e43, 2004.

[26] M. Goetz, S. Eichenlaub, G. R. Pape, and R. M. Hoffmann, "Chronic diarrhea as a result of intestinal microsposidiosis in a liver transplant recipient," Transplantation, vol. 71, no. 2, pp. 334-337, 2001.

[27] A. Sing, K. Tybus, J. Heesemann, and A. Mathis, "Molecular diagnosis of an Enterocytozoon bieneusi human genotype C infection in a moderately immunosuppressed human immunodeficiency virus-seronegative liver-transplant recipient with severe chronic diarrhea," Journal of Clinical Microbiology, vol. 39, no. 6, pp. 2371-2372, 2001.

[28] R. Kakrania, J. Joseph, P. K. Vaddavalli, N. Gangopadhyay, and S. Sharma, "Microsporidia keratoconjunctivitis in a corneal graft," Eye, vol. 20, no. 11, pp. 1314-1315, 2006.

[29] R. Kelkar, P. S. R. K. Sastry, S. S. Kulkarni, T. K. Saikia, P. M. Parikh, and S. H. Advani, "Pulmonary microsporidial infection in a patient with CML undergoing allogeneic marrow transplant," Bone Marrow Transplantation, vol. 19, no. 2, pp. 179-182, 1997.

[30] A. L. Galván, A. M. Martín Sánchez, M. A. Pérez Valentín et al., "First cases of microsporidiosis in transplant recipients in Spain and review of the literature," Journal of Clinical Microbiology, vol. 49, no. 4, pp. 1301-1306, 2011.

[31] A. Gamboa-Dominguez, J. De Anda, J. Donis, F. Ruiz-Maza, G. S. Visvesvara, and H. Diliz, "Disseminated Encephalitozoon cuniculi infection in a Mexican kidney transplant recipient," Transplantation, vol. 75, no. 11, pp. 1898-1900, 2003.

[32] A. R. Mohindra, M. W. Lee, G. Visvesvara et al., "Disseminated microsporidiosis in a renal transplant recipient," Transplant Infectious Disease, vol. 4, no. 2, pp. 102-107, 2002.

[33] M. A. Latib, M. D. Pascoe, M. S. Duffield, and D. Kahn, "Microsporidiosis in the graft of a renal transplant recipient," Transplant International, vol. 14, no. 4, pp. 274-277, 2001.

[34] B. George, T. Coates, S. McDonald et al., "Disseminated microsporidiosis with Encephalitozoon species in a renal transplant recipiente," Nephrology, vol. 17, pp. 5-8, 2012.

[35] D. P. Kotler and J. M. Orenstein, "Clinical syndromes associated with microsporidiasis," Advances in Parasitology, vol. 40, pp. 321-349, 1998. 


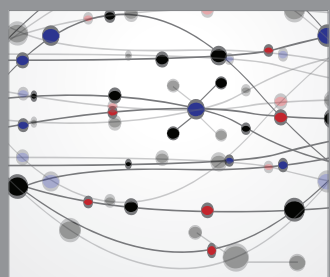

The Scientific World Journal
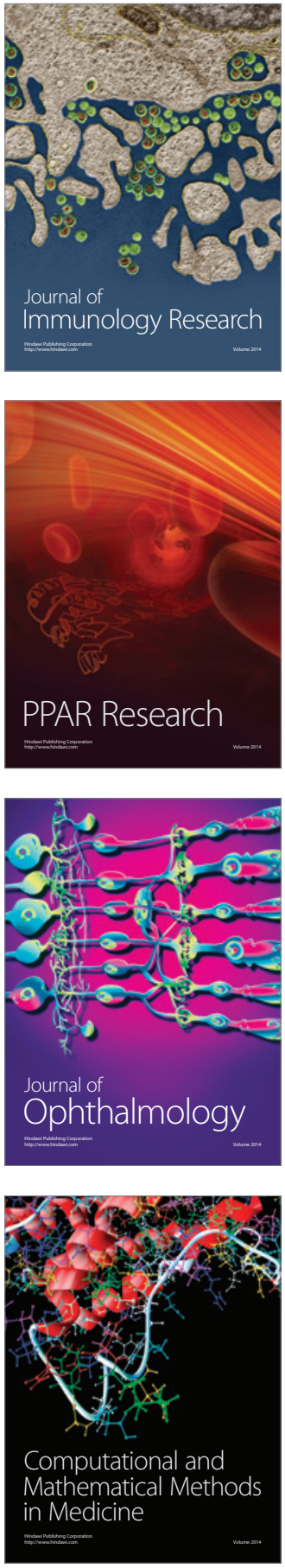

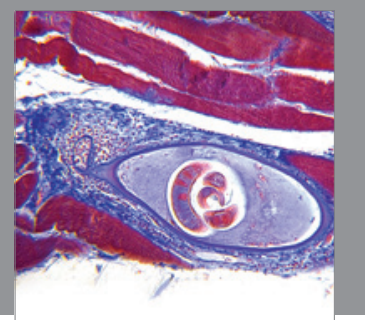

Gastroenterology

Research and Practice
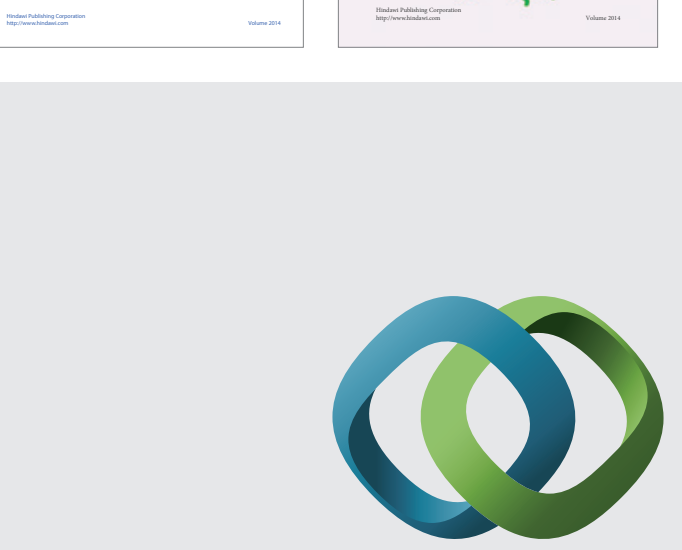

\section{Hindawi}

Submit your manuscripts at

http://www.hindawi.com
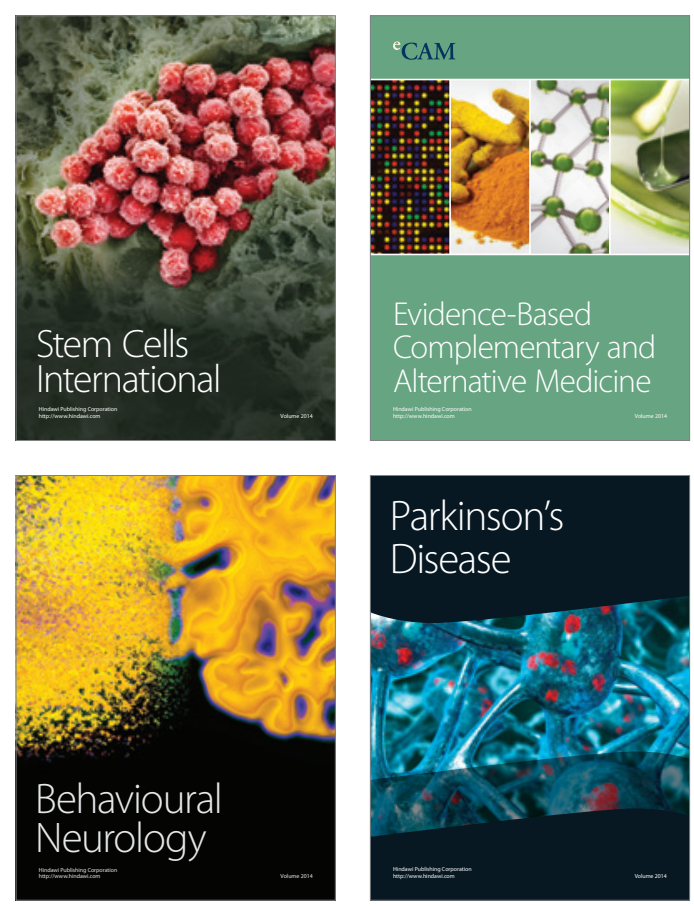

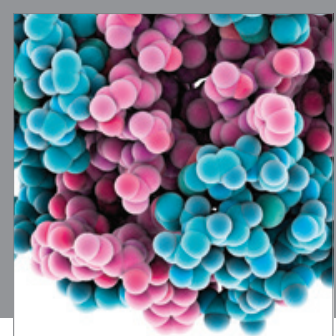

Journal of
Diabetes Research

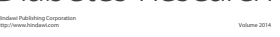

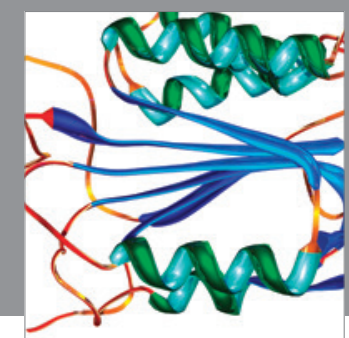

Disease Markers
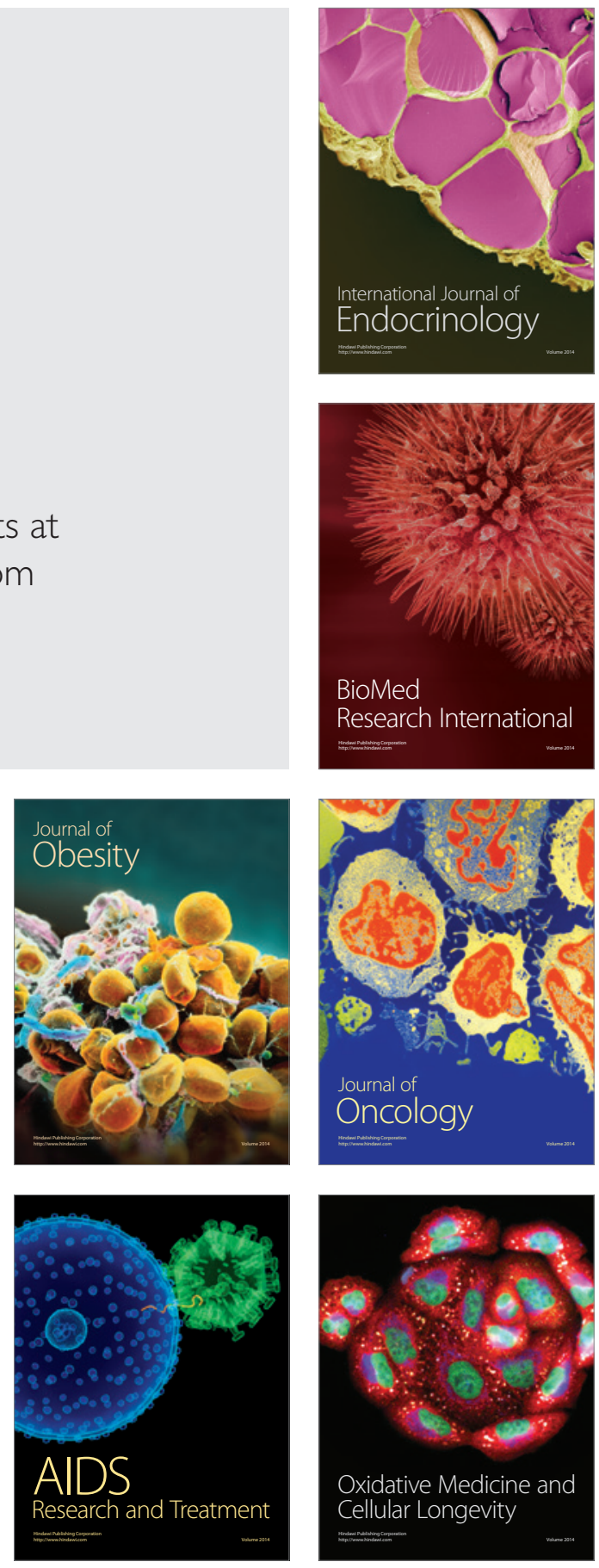